\title{
Bu open Objects of temporary contraception: an exploratory study of women's perspectives in Karachi, Pakistan
}

\author{
Kamyla Marvi, ${ }^{1}$ Natasha Howard ${ }^{2}$
}

To cite: Marvi K, Howard N. Objects of temporary contraception: an exploratory study of women's perspectives in Karachi, Pakistan. BMJ Open 2013;3: e003279. doi:10.1136/ bmjopen-2013-003279

- Prepublication history for this paper is available online. To view these files please visit the journal online (http://dx.doi.org/10.1136/ bmjopen-2013-003279).

Received 22 May 2013 Revised 4 July 2013 Accepted 5 July 2013
${ }^{1}$ Leadership Development for Mobilising Reproductive Health (LDM), Institute of International Education, Karachi, Pakistan

${ }^{2}$ Department of Global Health and Development, London School of Hygiene and Tropical Medicine (LSHTM), London, UK

Correspondence to Dr Natasha Howard; natasha.howard@Ishtm.ac.uk

\section{ABSTRACT}

Objectives: To explore perspectives of three modern contraceptive objects, using an emic approach, among women in a low-income community in Karachi, Pakistan.

Design: A qualitative interview study design was employed, using qualitative content analysis with an inductive approach and manual thematic coding.

Setting: Shah Faisal Colony, Karachi.

Participants: 20 women, potential contraceptive users of reproductive age and living within a health centre catchment, were purposively selected to provide a similar number of non-users $(n=5)$, contraceptive injection users $(n=7)$, pill users $(n=4)$, and intrauterine device users $(n=4)$. One interview was excluded because it was not recorded. No other exclusion criteria were used.

Primary and secondary outcome measures: The primary outcome was interpretation of potency and effects of selected family planning objects. Secondary outcome measures were knowledge of family planning and description of therapeutic approaches used and preferred.

Results: Awareness of family planning was high. Women described different therapeutic approaches, stating they generally preferred modern medicine for contraception as it was fastest and most powerful. They reported that fear of some contraceptive objects, particularly injections and intrauterine contraceptive devices, influenced their choices. Women explained their perceptions of how the heating effects of contraceptives could cause unwanted side effects including menstrual irregularities, weight gain and weakness, leading to disease.

Conclusions: Most women wanted family planning, but remained dissatisfied with the available contraceptives and their effects. While women reported that they relied on modern medicine for contraception, their descriptions of how contraceptives affected their health relied on the hot-cold explanatory idiom of traditional medicine.

\section{INTRODUCTION}

Pakistan, the world's sixth most populous country, has an estimated population of 176 million. ${ }^{12}$ The annual population growth of

\section{ARTICLE SUMMARY}

Article focus

- To explore women's understanding and interpretations of three modern contraceptives.

Key messages

- Women were knowledgeable about family planning and relied on modern contraceptives.

- Contraceptive potency and effects were interpreted using the hot-cold idiom of traditional medicine.

- Consideration of women's interpretive idioms could help providers improve health messages and family planning counselling.

Strengths and limitations of this study

- Use of qualitative methods provided rich insight into women's interpretations and decisionmaking regarding contraceptives.

- Available time and funding constrained the sample size, limiting the inclusion of a potentially broader range of perspectives.

$2.1 \%$ resulted in the population quadrupling in the past 50 years with $41 \%$ below age $15 .^{13}$ Potential reasons are both demandside (eg, female autonomy, religious beliefs, son preference ${ }^{4-7}$ ) and supply-side (eg, cost, poor distribution and limited coverage of contraceptives $\left.{ }^{8-10}\right)$. A rise in political and religious extremism since the dictatorship of Zia-ul-Haq (1977-1988), Pakistan's subsequent involvement in the international 'war on terror', poor governance and corruption have weakened the economy, worsening the social indicators. ${ }^{11}$ High population growth strains Pakistan's limited resources, affecting the health indicators. For example, with reproductive-age women constituting almost one-quarter of Pakistan's total population, a low contraceptive prevalence rate (CPR) of $29.6 \%$, with much lower rates among poor and rural populations, contributes to a high maternal mortality ratio of 260/100 000mostly preventable haemorrhage, eclampsia and sepsis. $^{151213}$ 
Pakistan has had a population programme since the 1960s and family planning awareness is nearly universal, with $96 \%$ of women surveyed identifying at least one modern contraceptive method. ${ }^{14}$ While modern contraceptives comprise $73 \%$ of Pakistan's CPR, temporary methods allowing birth spacing (eg, pills, intrauterine contraceptive device (IUDs), injectables, implants, condoms) comprise $13.6 \%$ of current usage, of which half $(6.8 \%)$ are condoms. ${ }^{1}$ Thus, only a small proportion of Pakistani couples use temporary methods, with evidence suggesting a significant unmet need for contraception (table 1). ${ }^{1} 1516$

Pakistan is a predominantly Muslim society with formal, informal and popular healthcare approaches coexisting. Pakistan's formal medical system includes modern (ie, Western) medicine, westernised homoeopathy, and traditional hikmat. Hikmat or unani tibb is traditional Greco-Arab medicine, widely practiced in Pakistan, with similarities to Indian Ayurvedic medicine. Modern medicine is the most common approach in urban settings and government facilities, but overlaps with traditional and folk approaches. ${ }^{17} 18$ Shaikh et al ${ }^{17}$ found that health providers often presented false qualifications or interpreted modern medicine to suit patient beliefs. While contraceptives are modern medicine, popular perceptions and practices are influenced by religion and other therapeutic approaches. ${ }^{12}{ }^{18}$ Nichter $^{19}$ noted that multiple therapy systems coexist in most countries, despite the regulatory efforts of government or vested interests of dominant therapy systems. Kleinman classified the professional, traditional, and popular as three overlapping systems, while Nichter found providers underappreciated the ways popular ideas about medicine influenced healthcare seeking and compliance. ${ }^{19-21}$

Women's perceptions of contraceptives significantly influence their decisions to start or continue family planning in Pakistan, supporting recent global discourse on the influences of side effects on usage. ${ }^{22-26}$ Bhatti et $a l^{27}$ found that $12.1 \%$ of non-users cited method-related reasons, including fear of side effects and interference with normal bodily processes. ${ }^{1}$ Sultana et $a l^{24}$ found that a $29 \%$ discontinuation rate for female methods in Punjab was primarily due to side effects, as contraceptive users associated all subsequent health problems (eg, obesity, body aches, high blood pressure, nausea, irregular bleeding and infertility) with contraceptive usage.

Most studies approach contraceptive behaviour from medical or behavioural perspectives, with minimal consideration of the contraceptive objects used. ${ }^{28}$ Such approaches can result in women's perspectives being minimised as misconceptions. ${ }^{29}{ }^{30}$ Little research has explored the explanatory models Pakistani women apply to their contraceptive beliefs. ${ }^{29}$ The term 'misconception' already implies that these beliefs are flawed and that the alternative medical model provides the correct explanation. However, these beliefs are entrenched in age-old belief systems and experiences that are real and personal to women and those around them. Nishtar found these beliefs to be based on societal perceptions, which women considered must have some basis in truth to be so widespread. ${ }^{29}$ Multiple sources of perception create the basis on which each woman makes decisions. ${ }^{31}$ The objects used for temporary contraception have their own potency to affect the body's functioning, the perceptions of which influence usage decisions (eg, whether, which, how long?). Little emic data, showing behaviour or beliefs in culturally meaningful terms, connect popular perceptions of contraception to usage. $^{32} 33$

This study examined perceptions of modern contraceptive objects, using an emic perspective, among women in a low-income community of Karachi, Pakistan. ${ }^{34}$ The research question was 'What are these women's beliefs about contraceptive objects and do those beliefs affect usage decisions?' It contributes to the literature on unmet need by describing how popular perceptions affect usage. Study objectives were to:

- Describe women's perceptions of three temporary contraceptives as objects (ie, injections, pills and IUDs);

- Consider how women's perceptions of contraceptive usage and potency within their own therapeutic paradigms affected usage decisions.

\section{METHODS}

Ethics approval was granted by the LSHTM research ethics committee in the UK and the Institutional Review

Table 1 Percentage method usage among married women aged $15-49$ years in Pakistan ${ }^{1}$

\begin{tabular}{|c|c|c|c|c|c|c|c|c|c|c|c|c|}
\hline \multirow[b]{2}{*}{ Method } & \multirow[b]{2}{*}{$\begin{array}{l}\text { Current } \\
\text { usage }\end{array}$} & \multirow[b]{2}{*}{$\begin{array}{l}\text { Ever } \\
\text { used }\end{array}$} & \multicolumn{2}{|c|}{ Residence } & \multicolumn{3}{|c|}{ Education } & \multicolumn{5}{|c|}{ Wealth Quintile } \\
\hline & & & Urban & Rural & Illiterate & $\begin{array}{l}\text { Primaryl } \\
\text { secondary }\end{array}$ & Higher & 1 & 2 & 3 & 4 & 5 \\
\hline Hormonal pill & 2.1 & 12.2 & 2.6 & 1.8 & 2.0 & 2.0 & 2.9 & 1.5 & 1.8 & 1.9 & 2.6 & 2.4 \\
\hline $\begin{array}{l}\text { Injectable } \\
\text { contraceptive }\end{array}$ & 2.3 & 11.1 & 2.3 & 2.3 & 2.1 & 2.9 & 1.1 & 1.6 & 2.5 & 3.2 & 2.7 & 1.6 \\
\hline $\begin{array}{l}\text { Intrauterine } \\
\text { contraceptive device } \\
\text { (IUD) }\end{array}$ & 2.3 & 8 & 2.6 & 2.1 & 1.9 & 2.6 & 4.5 & 1.0 & 1.5 & 2.8 & 1.7 & 4.8 \\
\hline
\end{tabular}


Board of Interactive Research and Development in Pakistan.

With approximately 18 million inhabitants, Karachi is the commercial, industrial and financial hub of Pakistan (figure 1). ${ }^{35}$ Shah Faisal Colony (figure 2), with a population of over 335000 , has experienced violent civil clashes. It was chosen for its ethnic diversity and low socioeconomic level. A local non-governmental organisation, Rana Liaquat Craftsman Colony (RLCC), provided a community entry point, facilitating access to women. RLCC has provided basic clinic services in Shah Faisal Colony since 1954, providing services to approximately 5400 families. Women living in the study site have access to contraceptives through door-to-door distribution of condoms and pills, and clinical access to IUDs and injectables through NGO workers. Contraceptives were sold for Pakistani Rupee 1 (US\$0.01) per condom, Pakistani Rupees 10 (US\$0.10) for oral pills, Pakistani Rupees 100 (US\$1.0) for 3-month injectables and Pakistani Rupees 300 (US\$3.0) for IUD insertion.
In-depth face-to-face interviews were chosen to explore women's experiences and perceptions. Twenty participants were purposively sampled, for diversity of opinion, from the population of non-menopausal married women over age 20, living in Shah Faisal Colony, Karachi. No other inclusion and exclusion criteria were used. Researchers aimed for:

- 5 non-users of contraception;

- 5 injectable contraceptive users (1-month, 2-month or 3-month dosage);

- 5 oral pill users;

- 5 IUD users.

Participants were recruited by RLCC outreach workers, trained for 1 day in qualitative recruitment methods, who distributed study information sheets and obtained written informed consent from all literate potential participants. Verbal consent was taken from illiterate participants after reading out and discussing the information sheet and consent form with them. The lead author was responsible for final participant

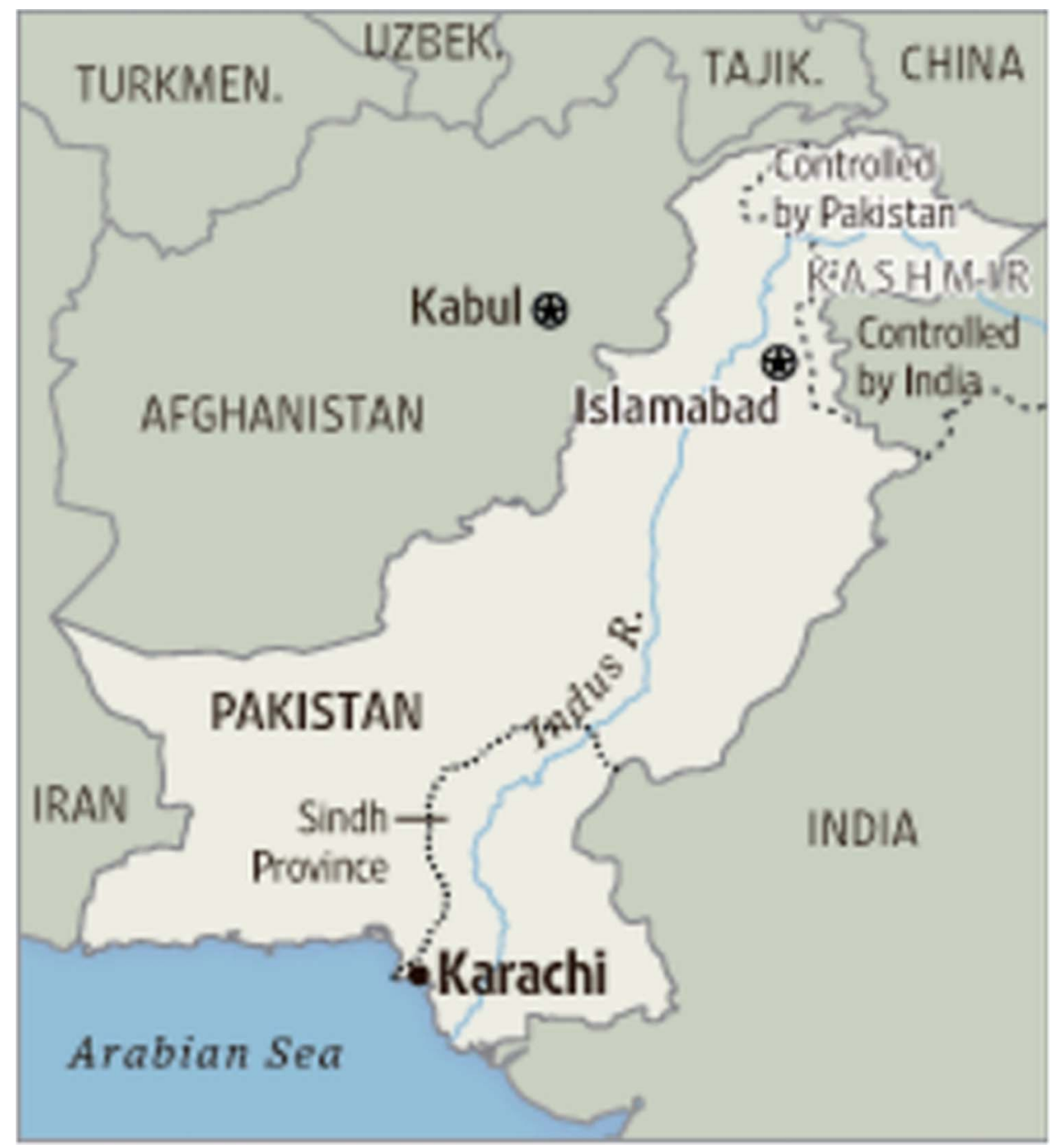

Figure 1 Map of Pakistan. 


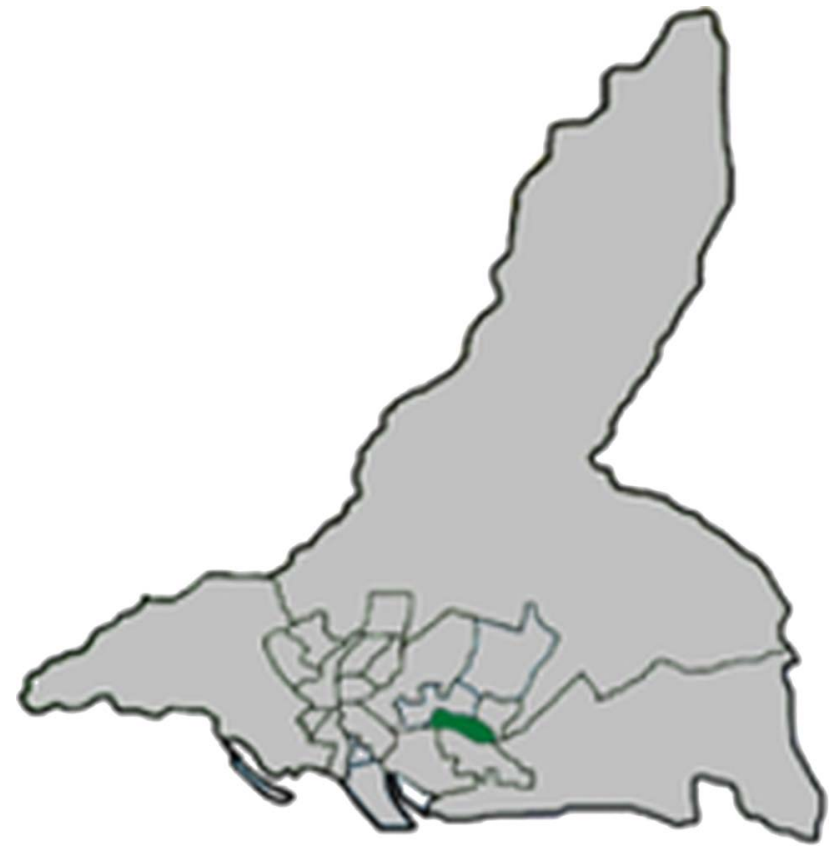

Figure 2 Schematic map of Karachi showing the location of Shah Faisal Colony.

selection, reconfirmation of consent and conducting interviews in a private room at the RLCC health centre. Two pilot interviews were conducted to finalise the interview guide. The guide ensured that themes of interest were covered, though interviews were conducted as loosely guided conversations to allow women control in defining topics. Interviews were digitally recorded with participant permission and took approximately $1 \mathrm{~h}$. Recordings were given a pseudonym to ensure confidentiality, which was also recorded on the consent form and kept in a locked file. Observations were recorded for each interview.

Interviews were transcribed in Urdu, translated into English, and typed into Microsoft Word by a professional transcriptionist and translator familiar with reproductive health terminology. Translations were checked by the interviewer, and participants where possible, to ensure accuracy. Transcripts were labelled with pseudonyms and numbered by page and line.

Following principles of interpretive social research, the interviewer conducted initial analysis to increase interpretability and deepen understanding of social and emotional context. ${ }^{36}$ Qualitative content analysis with manual thematic coding was used, with an inductive approach to building non-hierarchical themes and identifying meaning. ${ }^{37}$ Consensus was reached between authors on differences found. Data were triangulated by comparing responses to similar questions in different transcript sections.

\section{FINDINGS}

Twenty-one interviews were conducted. One, unrecorded, was excluded. Of 20 participants (table 2), 6 were illiterate and others educated to secondary level, with 2 completing matriculation after grade 10 and 5 completing intermediate certification after grade 12 . Most (ie, 13 women) were housewives, three did piecework embroidery at home, and a few had outside jobs (eg, domestic work, teaching, one actress). Half of the husbands (ie, 11) worked in low-income jobs (eg, street merchants), six were semiskilled or skilled labourers (eg, electrician, driver and barber), while two husbands were unemployed. Women were of various ethnicities, including three Pathans, five Muhajir and seven Punjabis. All were Muslim and most had resided in the area since childhood (7) or marriage (11). Participants averaged 31 years of age (25-45 years), were married and still menstruating. Non-users were, on average, 10 years older than contraceptive users (38 vs 28). All had children, ranging from 7 months to 25 years of age. Participants had an average of three children each (range 1-10). Non-users had fewer male children on average, at 0.80 male and 2.6 female vs 1.5 male and 1.6 female for contraceptive users. Of the 15 contraceptive users, 7 used injectable contraceptives, 4 used contraceptive pills, and 4 used an IUD. Thirteen contraceptive users cited the expense of raising children as their primary reason for birth spacing, while two cited previous pregnancy complications.

Emergent themes are organised under therapeutic systems, contraceptives as objects, and potency and side effects.

\section{Therapeutic systems}

All women discussed multiple therapeutic systems, including doctors practicing through private and government services, lady health workers, traditional birth attendants, homoeopaths, hakeems, and practitioners offering healing prayers. ${ }^{17}$ Most women used home remedies and explored different systems with varying success:

Talat: Yes we have tried all. We have had prayers done; we have taken medicines from doctors, and hakeems too. Some are good and effective.

Nadira: For example, a complete treatment for jaundice does not exist in modern medicine, which simply advises to take more water and juices; but homeopathy has the treatment for this.

Women preferred the speed and power of modern treatments:

Talat: Most of the time we take medicines from doctors [because] we get relief more quickly. Children get better. Rather then taking remedies we more often take medicine from outside so that the children can be comfortable more quickly. They shouldn't suffer.

Rehmat: The difference is that the homeopathic impact is very late, and modern medicine, such as injections etc., has an immediate effect...A person recovers immediately. 
Table 2 Participant demographics, ordered by contraceptive usage and age

\begin{tabular}{|c|c|c|c|c|c|c|}
\hline \multirow[b]{2}{*}{ Pseudonym } & \multirow[b]{2}{*}{ Usage } & \multirow[b]{2}{*}{ Age } & \multirow[b]{2}{*}{ Education } & \multirow[b]{2}{*}{ Origin } & \multicolumn{2}{|c|}{$\begin{array}{l}\text { Living } \\
\text { children }\end{array}$} \\
\hline & & & & & $\overline{\mathbf{M}}$ & $\mathbf{F}$ \\
\hline Ayesha & Non-user & & Grade 9 & Haripur & 2 & 1 \\
\hline Nadira & Non-user & 31 & Intermediate & Pindi & 0 & 2 \\
\hline Kaukab & Non-user (pregnant) & 37 & Grade 5 & Abbasi & 0 & 4 \\
\hline Rashida & Non-user & 40 & Grade 9 & - & 0 & 5 \\
\hline Aziza & Non-user & 45 & Matriculation & Muhajir & 2 & 1 \\
\hline Karima & Injection & 25 & Grade 8 & Punjabi & 1 & 0 \\
\hline Sofia & Injection & $25-26$ & Grade 8 & - & 1 & 2 \\
\hline Farida Bibi & Injection & 28 & Intermediate & - & 1 & 0 \\
\hline Rehmat & Injection & 28 & Intermediate & Muhajir & 2 & 0 \\
\hline Talat & Injection & 28 & Illiterate & Punjabi & 0 & 4 \\
\hline Gul Zehra & Injection & 33 & Illiterate & Pathan & 2 & 8 \\
\hline Nasreen & Injection & 35 & Matriculation & Punjabi & 2 & 1 \\
\hline Misbah & Pills & & Illiterate & Pathan & 1 & 1 \\
\hline Qamar & Pills & 23 & Grade 8 & Punjabi & 1 & 1 \\
\hline Pari & Pills & 28 & Illiterate & Punjabi & 2 & 2 \\
\hline Insiya & Pills & 28 & Intermediate & - & 2 & 1 \\
\hline Shazia & IUD & & Illiterate & Punjabi & 1 & 1 \\
\hline Mariam & IUD & $<30$ & Illiterate & Pathan & 1 & 2 \\
\hline Shaista & IUD & 30 & Intermediate & Muhajir & 2 & 1 \\
\hline Shehnaz & IUD & 31 & Grade 8 & Muhajir & 3 & 1 \\
\hline
\end{tabular}

NB: Education in Pakistan is organised into primary (grades 1-5); middle (grades 6-8); high (grades 9-10, culminating in matriculation);

intermediate (grades 11-12, culminating in intermediate diploma).

Farida Bibi: Very few people go to a Hakeem; and those that do are elderly. I mean to say, those who, because of their age are unable to use the medicines of a doctor as they are of greater power, they go to a Hakeem.

Women used home remedies or modern services for reproductive issues. Most chose delivery in hospitals or maternity clinics, with only four reporting giving birth with the help of a $d a i$ or traditional birth attendant. Nineteen of 20 participants expressed eagerness to space their children. Non-users spoke of birth spacing through breastfeeding or other natural methods, with one woman using withdrawal. Participants were not asked about birth limiting versus birth spacing. All women preferred modern contraceptives, and knew of no methods emerging from alternative therapy systems.

\section{Contraceptives as objects}

Women were shown injectable contraceptives, pills and IUDs during interviews to elicit their perceptions.

All were familiar with injections as objects, as Pakistani practitioners commonly overprescribe them. ${ }^{38}$ Women expressed different levels of fear, from mild to much stronger discomfort

Rehmat: The [contraceptive] injection hurts so much that I get shaken up, although I try to control myself. She says to leave the body loose, but when an injection is going inside, how I can leave it loose? My leg becomes numb. She says 'I don't know - this doesn't happen with anyone else, just you...'
Some women said injections generally were a more powerful and faster way of delivering medicine to the body.

Rehmat: When we eat medicine, it affects after a while. Injections effect immediately, they mix with the blood quickly.

Most women said contraceptive pills were easy to use, some suggesting they were mild or weak because they were small and needed to be taken daily.

Insiya: These are so small. One doesn't even feel that one has taken something.

One woman explicitly related size to potency

Ayesha: Due to size they may have greater potency, the ones that are large-sized...

Interviewer: And this one that is small? (pointing to contraceptive pills)

Ayesha: It may be of lesser potency.

Women expressed the greatest fear of IUDs. Vaginal insertion already brings a sense of discomfort within the cultural milieu of Muslim women. Many who commented were less familiar with IUDs, and several expressed hesitation about inserting a foreign object into the body. 
Insiya: When I went to get injected they showed me the IUD, that either I should use the injection or the IUD, but the mere sight of it appeared to be something dangerous

\section{Several worried it would hurt their husbands}

Shazia: Yes, he experiences inconvenience. It is that wirelike thing, it sticks to him. He scolds me, 'Why did you get this done?' Later on he becomes normal. He says it is all right.

Several expressed concern about potential risks from IUD materials

Misbah: Plastic and flesh are different, it will do some harm.

Interviewer: This is plastic, that's why it will cause problems?

Misbah: Yes, it's plastic. That's why it causes some problem or another.

Interviewer: What problem?

Misbah: I don't know, but I don't find it good.

Shaista: Now copper is kept inside the wet body and something keeps on releasing from it. This is what people say. People used to tell me that it is rust and when it rusts from inside it will produce fungus inside the uterus and obviously fungus will be converted into cancer and many people complain of cancer.

\section{Potency and side effects}

Colour

Most stated that an object's colour did not affect its potency but helped with identification. A few noted that lighter colours meant the medicine was gentler.

Shaista: Obviously light colour medicines are more suitable and better, you might have seen that iron syrups are darker in colour and they have a different taste. When you drink it you will feel that you have eaten iron. It emits a smell like iron and does not suit us.

\section{Heat}

Nearly all discussed medicinal potency and effect on their well-being in terms of heating (garam taseer) and cooling (thandi taseer) properties. Participants considered modern medicine heat generating and other therapies less so.

Farida Bibi: One hears that the medicines of the Hakeem are herbal and they are cooling. Even if these medicines do not bring relief, they do not cause harm.

All women identified contraceptives as 'heating,' with pills and injections particularly being considered more heating than other modern medicines
Ayesha: These things generate heat into one's body; one feels upset. If I take a tablet I feel uneasy and my heart pounds.

Interviewer: What is its effect?

Qamar: It is hot...

Interviewer: Are all tablets hot?

Qamar: Some are hotter than others.

Interviewer: Do you think these [contraceptives] are hotter or cooler?

Qamar: Yes, these are hotter.

Women described the heating effect of contraceptives as resulting in, or further accentuating, irregular or excessive menstruation, weakness and weight gain. Most said contraceptive heat resulted in excess bleeding.

Shehnaz: I got it [IUD] placed that's why I have more flow of menstruation; that happens with everyone.

Several equally interpreted missed menstruation as heat damage, discussing herbal remedies to encourage the onset of delayed menstruation

Nasreen: Obviously, they [contraceptive injections] are heat-generating. They may be burning the blood.

Interviewer: What do you mean by burning the blood as you cannot see the process?

Nasreen: Just what elder women say; girls take injections; the blood gets burned; there is no menstruation.

Others focused on weakness and swelling.

Pari: If a woman is weak she shouldn't take it. I know how difficult it is for me. She won't tolerate it well. She will be so tired from taking pills. They are very hot and because they are hot they will rot your blood. You will feel unwell.

Nadira: I was not like I am today. There is more swelling in my body. When one takes more medicines, I think it harms the body.

Interviewer: You are saying that it is due to hot medicines?

Nadira: Yes it is due to heat.

\section{Menstruation}

A regular flow of menstruation was considered normal and healthy by all women. Women associated irregular bleeding with weakness, weight gain and disease. Women associated menstrual irregularities with all three contraceptives, but those using injectables complained most. 
Nasreen: I stopped taking [contraceptive] injections; I say that the flow of menstruation is also essential.

Most reported menstruation as a form of cleansing. If it did not occur regularly then weight gain or serious disease could follow.

Farida Bibi: I too fear that my periods may stop and that my abdomen starts bulging.

Nasreen: They say that if menstruation stops it causes internal diseases. Tumours are formed, obviously, if something dirty doesn't find its way out.

Women associated both excessive and insufficient menstruation with weakness. Perspectives varied as to whether weakness caused irregular bleeding or vice versa.

Farida Bibi: Some have excessive menses; they have it twice a month; as a result of which one gets weaker. For example, in our home there is my elder sister-in-law; it [IUD] did not suit her. She goes through excessive menstruation, even more than before. She is getting weaker day by day.

Talat: When it used to come every month it was ok. Now it is every $2-3$ months. Then sometimes it is scanty and sometimes it is heavy.

Interviewer: How does that affect a woman?

Talat: It causes weakness. When women menstruate, then weakness is relieved.

\section{Long-term effects}

Women's perspectives were mixed whether long-term or repeated usage of contraception was harmful. Some, who felt comfortable with their method of contraception, said that extended usage of 5-10 years was harmless:

Ayesha: What effect would it be? No, nothing...

Interviewer: Nothing?

Ayesha: It depends on you. You should take care of yourself.

Others were concerned about blood pressure, infertility, uterine damage, obesity and "problems with the blood'. The most common concern was temporary infertility

Talat: You won't get pregnant. When the effect of medicine finishes in the body, then pregnancy occurs. My niece had the injection. When she left the injection, a year or so after, when the effect of the medicine finished, she conceived.
Nasreen: If you use something in routine you should give a gap in between...

Interviewer: So if I desire child spacing of five years and if I use injections continuously?

Nasreen: No, don't do that!

Interviewer: What is the risk involved in that?

Nasreen: The risk is that the menstruation will stop altogether.

Interviewer: So is that risky?

Nasreen: Yes, that is dangerous!

One participant stated that prolonged usage of medicines reduces efficacy

Rashida: Anything stops having an effect. If you continuously use a medicine its effect finishes.

\section{Suitability}

While women said all medicines are heat generating, they clarified that the extent to which heating effects were felt depended on the person's blood. People have hot or cold blood, which reacts to hot or cold foods and medicines. Hot-blooded people were described as more sensitive to heat, getting rashes and being irritable by nature.

Aziza: Yes. It [blood] is hot or cold, depending on the person's body makeup. We practice remedies by ourselves... for decreasing the heat of the body.

Women discussed how contraceptives 'suit' or do not suit an individual. Many tried one method and then switched to another because it did not suit them. Women understood each person to be different, and that each method had different effects on different people.

Pari: Everyone says that the tube [IUD] suits some people and is better, but others whom it does not suit, it causes damage.

Qamar: If it suits a woman, then they keep taking. And there are some women, like me, the [contraceptive] injection harmed me, so I left it. Like these pills now suit me, in the same way there are some women whom the injection suits. Then they keep using the injection.

Women discussed how, after some time, the negative effects of medicines could wear off and suit them better.

\section{DISCUSSION}

Participants were familiar with the strengths and weaknesses of multiple therapeutic approaches, and moved easily between them, depending on the nature of the 
problem and whether the initial approach was considered effective. Women generally preferred modern approaches as providing more powerful and rapid results—and as the only choice for fertility control—but expressed concerns about the long-term effects. Concepts of medicinal potency reflected those in other studies. For example, Nichter ${ }^{19}$ reports that Indian villagers perceived that modern medicine offered a quick cure but eventually harmed overall health.

The contraceptive as an object was meaningful for women. Particularly meaningful were fear of injection pain and discomfort about IUD usage, both affecting contraceptive choices. ${ }^{36}{ }^{39}$ Despite preferring modern contraception, women used traditional medicine idioms to explain contraceptive objects and how these worked within their bodies. Women's perceptions of how contraceptives affected their health were grounded in the hotcold explanatory idiom. ${ }^{40}$ This idiom of the heating and cooling effects of food and medicine, combined with an individual's hot or cold blood, is found in many traditional health approaches including Chinese, North Indian and South American. ${ }^{41-46}$ The hot-cold concept is rooted in Hippocratic humoral medicine that spread via Arab influence. ${ }^{43}$ Nichter ${ }^{19}$ describes Western medicines as heating and ayurvedic medicines as neutral, in reference to the speed and uncontrolled manner in which the former acts and the perceived effect on the blood.

In Pakistan, the hot-cold idiom is an essential component of hikmat. Although hikmat was not a preferred therapeutic approach for participants, this idiom was essential to their understanding of the effects of contraceptives on their bodies and why individuals reacted differently. Women reported menstrual irregularities, weight gain and weakness as the main interconnected problems caused by the heating properties of contraceptives. While no other literature from Pakistan was found relating women's perceptions of contraception to this idiom, it was overwhelmingly part of the participants' vocabulary. Weakness from already heated blood could be further aggravated by the heating effects of contraceptives. Women spoke of discontinuing or changing methods because of such side- effects, supporting Casterline and coworkers' conclusion that widespread concerns about adverse health consequences act as a barrier to the adoption and continued usage of contraceptives. ${ }^{1025}$

Women worldwide have perceptions about menstrual bleeding and what is normal and natural. Participants perceived a regular menstrual flow as healthy. Similarly, women in Mali and South Africa equated menstruation with the womb being cleared of 'dirt,' thus allowing good health, so methods that interrupt the natural menstrual pattern were considered unacceptable. ${ }^{25}$ Participants associated menstrual irregularities (eg, reduced or increased flow) with dangerous outcomes from bloodlessness, weight gain and disease and related them causally to the heating effects of contraceptives.
Thus, injections were often perceived as the most heating since they most often led to menstrual irregularities. Several women used nutritional and herbal remedies to counteract the side effects of modern medicines such as contraceptives, usually the perceived heating and weakening effects. ${ }^{17} 18$

This exploratory study drew from the experiences of a small sample of 20 women, most of whom had experience of using some or all of the contraceptives discussed. Data saturation was not attempted due to time and security concerns. However, the findings-particularly regarding the importance of the hot-cold idiom and menstrual regularity-suggest opportunities for further research.

\section{CONCLUSIONS}

The study findings support existing research on contraceptive usage. Most women wanted family planning, but were not entirely comfortable with their experiences of contraceptive use. The Pakistan government implements a nationwide Lady Health Worker Programme through the Provincial Health Departments, and a Family Welfare Worker Programme through the Population Welfare Departments of each province. These aim to provide PHC services including door-to-door family planning counselling and distribution to women in their homes. A better understanding of women's concerns and explanatory models could provide more effective service delivery for family planning. Women's concerns regarding the family planning side effects and resulting health concerns could also inform the research and development of contraceptives. The limitations of today's contraceptive technology are one reason that women are not using, or are uncomfortable with using, family planning methods. Thus, the findings provide explanatory models from women themselves that could, with further research, inform health messages and family planning counselling, strengthening programmes in Karachi and potentially elsewhere in Pakistan.

Acknowledgements The authors thank the women from Shah Faisal Colony who shared their perspectives and experiences. They also thank the RLCC health team for their facilitation and support.

Contributors Both authors contributed substantially to the study design and data interpretation. KM conceived of the study, collected the data and drafted the article, with critical input and revision from NH. Both authors approved the final version before publication.

Funding This research received no specific grant from any funding agency in the public, commercial or not-for-profit sectors.

Competing interests None.

Ethical approval The study was approved by the ethics committee of the London School of Hygiene and Tropical Medicine (LSHTM) in the UK and the Institutional Review Board of Interactive Research and Development in Pakistan.

Provenance and peer review Not commissioned; externally peer reviewed.

Data sharing statement No additional data are available.

Open Access This is an Open Access article distributed in accordance with the Creative Commons Attribution Non Commercial (CC BY-NC 3.0) license, 
which permits others to distribute, remix, adapt, build upon this work noncommercially, and license their derivative works on different terms, provided the original work is properly cited and the use is non-commercial. See: http:// creativecommons.org/licenses/by-nc/3.0/

\section{REFERENCES}

1. NIPS. Pakistan demographic and health survey 2006-2007. Islamabad: National Institute of Population Studies, 2007

2. PCO. Estimated population of Pakistan. Secondary estimated Population of Pakistan. 2011.

3. World Bank. Data on annual population growth (\%). 2011. http:// data.worldbank.org/indicator/SP.POP.GROW (accessed Dec 2012).

4. Zafar MI. Husband-wife roles as a correlate of contraceptive and fertility behaviour. Pak Dev Rev 1996;35:145-70.

5. Mahmood N, Ringheim K. Factors affecting contraceptive use in Pakistan. Pak Dev Rev 1996;35:1-22.

6. Nasir JA, Hinde A. Factors associated with contraceptive approval among religious leaders in Pakistan. JBiosoc Sci 2011;43:587-96.

7. Saleem A, Pasha GR. Women's reproductive autonomy and barriers to contraceptive use in Pakistan. Eur J Contracept Reprod Health Care 2008;13:83-9.

8. GoP. Development Amidst Crisis, Pakistan Millennium Development Goals Report Islamabad. Centre for Poverty Reduction and Social Policy Development, Planning Commission, 2010.

9. Fikree FF, Saleem S, Sami N. A quality of care issue: appropriate use and efficacy knowledge of five contraceptive methods: views of men and women living in low socioeconomic settlements of Karachi, Pakistan. J Pak Med Assoc 2005;55:363-8.

10. Casterline JB, Sathar ZA, ul Haque M. Obstacles to contraceptive use in Pakistan: a study in Punjab. Stud Fam Plann 2001;32:95-110.

11. Javaid U. Corruption and its deep impact on good governance in Pakistan. Pak Econ Soc Rev 2010;48:123-34.

12. Zafar MI, Ford N, Ankomah A. Significance of beliefs and values in predicting fertility and contraceptive behaviour in Pakistan. J Biosoc Sci 1995;27:301-18.

13. Jafarey SN. Maternal mortality in Pakistan-compilation of available data. J Pak Med Assoc 2002;52:539-44.

14. Hamid S, Stephenson R. Provider and health facility influences on contraceptive adoption in urban Pakistan. Int Fam Plann Perspect 2006;32:71-8.

15. Shaikh B. Unmet need for family planning in Pakistan-PDHS 2006-2007: it's time to re-examine déjà vu. Open Access J Contracept 2010;1:113-18.

16. Carton TW, Agha S. Changes in contraceptive use and method mix in Pakistan: 1990-91 to 2006-07. Health Policy Plan 2012;27:166-74.

17. Shaikh $\mathrm{SH}$, Malik F, James $\mathrm{H}$, et al. Trends in the use of complementary and alternative medicine in Pakistan: a population-based survey. J Altern Complement Med 2009;15:545-50.

18. Shaikh BT, Hatcher J. Complementary and alternative medicine in Pakistan: prospects and limitations. Evid Based Complement Altern Med 2005;2:139-42

19. Nichter M. The layperson's perception of medicine as perspective into the utilization of multiple therapy systems in the Indian context. Soc Sci Med Med Anthropol 1980;14B:225-33.

20. Kleinman A. Patients and healers in the context of culture: an exploration of the borderland between anthropology, medicine, and psychiatry. University of California Press, 1980

21. Kleinman A. The illness narratives: suffering, healing, \& the human condition. Basic Books, 1988.

22. Tolley E, Loza S, Kafafi L, et al. The impact of menstrual side effects on contraceptive discontinuation: findings from a longitudinal study in Cairo, Egypt. Int Fam Plann Perspect 2005;31:15-23.
23. Godfrey EM, Chin NP, Fielding SL, et al. Contraceptive methods and use by women aged 35 and over: a qualitative study of perspectives. BMC Women's Health 2011;11:5.

24. Sultana A, Qazilbash A. Factors associated with failure of family planning methods in Pakistan: Burhan village case study. Working Paper Series \#91. Islamabad: Sustainable Development Policy Institute, 2004

25. Williamson LM, Parkes A, Wight D, et al. Limits to modern contraceptive use among young women in developing countries: a systematic review of qualitative research. Reprod Health 2009;6:3.

26. Zafar M, Habib-Ullah M, Rehman S, et al. Fertility regulating behaviour: a study of rural Punjab-Pakistan. Pak J Appl Sci 2003;3:376-84.

27. Bhatti $\mathrm{MH}$. Correlates of choice of contraceptive methods in Pakistan. Pak Dev Rev 1995;34(4 Pt III):889-98.

28. Rajasekar D, Bigrigg A. Pill knowledge amongst oral contraceptive users in family planning clinics in Scotland: facts, myths and fantasies. Eur J Contracept Reprod Health Care 2000;5:85-90.

29. Aleem N. Myths and misconceptions about contraceptive methods: an exploratory qualitative study amongst married youth of Karachi. Aga Khan University, 2010.

30. Ali S, Sophie R, Imam AM, et al. Knowledge, perceptions and myths regarding infertility among selected adult population in Pakistan: a cross-sectional study. BMC Public Health 2011;11:760.

31. Harcourt W. Sex, lies and population: a view from the north? Working Paper Series \#3. Islamabad: Sustainable Development Policy Institute, 1992

32. Spiers J. New perspectives on vulnerability using emic and etic approaches. J Adv Nurs 2000;31:715-21.

33. Scherer RF, Owen CL, Petrick JA, et al. Initial development of an emic methodology for classification of stressful work situations. Percept Mot Skills 1991;73(3 Pt 1):1004-6.

34. Tripp-Reimer T. Reconceptualizing the construct of health: integrating emic and etic perspectives. Res Nurs Health 1984;7:101-9.

35. Karachi City Government. Shah Faisal Town. City District Government, Karachi, 2011. http://www.karachicity.gov.pk/ (accessed Sep 2012)

36. Higgins JA, Hirsch JS. Pleasure, power, and inequality: incorporating sexuality into research on contraceptive use. $A m \mathrm{~J}$ Public Health 2008;98:1803-13.

37. Smith C. Content analysis and narrative analysis. In: Reis $\mathrm{H}$, Judd C. eds. Handbook of research methods in social and personality psychology. Cambridge University Press, 2000.

38. Kamran I, Arif MS, Vassos K. Concordance and discordance of couples living in a rural Pakistani village: perspectives on contraception and abortion-a qualitative study. Global Public Health 2011;6(Suppl 1):S38-51.

39. Kaneshiro B, Aeby T. Long-term safety, efficacy, and patient acceptability of the intrauterine Copper T-380A contraceptive device. Int J Women's Health 2010;2:211-20.

40. Pool R. Hot and cold as an explanatory model: the example of Bharuch district in Gujarat, India. Soc Sci Med 1987;25:389-99.

41. Barrett RJ, Lucas $\mathrm{RH}$. Hot and cold in transformation: is Iban medicine humoral? Soc Sci Med 1994;38:383-93.

42. Harwood A. The hot-cold theory of disease. Implications for treatment of Puerto Rican patients. JAMA 1971;216:1153-8.

43. Hartog J, Hartog EA. Cultural aspects of health and illness behavior in hospitals. West J Med 1983;139:910-16.

44. Hilgert NI, Gil GE. Reproductive medicine in northwest Argentina: traditional and institutional systems. J Ethnobiol Ethnomed 2007;3:19

45. Singh A. Place of menstruation in the reproductive lives of women of rural North India. Indian J Community Med 2006;31:10-14.

46. Marcos S. Hot and cold classification in traditional Iguape medicine. Ethnology 1984;23:63-72. 